pesticides have yielded inconclusive results about the risks presented.' Effective safety margins, based on the best risk assessment models and full information, are necessary in making decisions regarding environmental health policy because of this uncertainty. Yet, remarkably, no published comprehensive British environmental health impact assessments or audits of pesticides seem to exist. The British process of registering pesticides does not entail effective audit or environmental health impact assessments.

Potential environmental health effects of pesticides must be assessed from the start of the extraction process for basic chemicals to the end of the waste disposal process and residue chain. This does not happen. Information on the pollution effects and health effects of energy used in manufacturing and transporting materials for pesticides is not readily available. Data on resistance of pests and damage to beneficial predators on pests resulting from use of pesticides are lacking. Knowledge of possible pollution effects of pesticides is still limited.

Pesticides occur in rain $^{6}$ and fog $^{7}$ and as pollutants of materials and atmospheres in various buildings. Researchers have found many pesticide residues in the air and house dust of homes. ${ }^{8} \mathrm{~A}$ study recently showed that over nine months the potential exposure of a crawling infant to flea pesticides could exceed the World Health Organisation's no observable effect levels. ${ }^{9}$ Full audits and environmental health impact assessments of pesticides would identify such potential sources of pollution, would ensure a better assessment of any chemical's impact on the environment, and should be introduced into all relevant legislation in the United Kingdom. This requires active medical participation to monitor and predict the effects of environmental pollution on health and to ensure that Britain endorses the highest environmental standards. ${ }^{10}$

ANDREW WATTERSON

Workplace Health, Safety, and Environment Research Group,

University of Southampton

Southampton SO95NH

Wessex Regional Health Authority,

HUGH THOMAS

Winchester,

Hampshire SO225DH

1 Godlee F. Strategy for a healthy environment. BMf 1991;303. 836-8. (5 October.)

2 Go F. Environmental impact assessment. London: Monitoring and Assessment Research Centre, World Health Organisation, United Nations Environment Programme, 1987.

3 Watterson A. Pesticides and your food. London: Greenprint, 1991.

4 Walker A. Drinking water-doubt about quality. $B M \mathcal{F}$ 1992;304:175-8. (18 January.)

5 British Medical Association. Guide to pesticides, chemicals and health. London: Edward Arnold, 1992

6 Richards RP, Kramer JW, Baker DB, Krieger KA. Pesticides in rainwater in the NE United States. Nature 1987;327:129-31.

7 Glotfelty DE, Seiber JN, Liljedhal. Pesticides in fog. Nature 1987;325:602-5

8 Immerman FW, Schaum JL. Non-occupational pesticide exposure study. Springfield, Virginia: United States Environmental Protection Agency, 1990. (PB 90-152 224/AS National Technical Service.

9 Fenske RA, Black KG, Elkner KP, Lee C, Methner MM, Soto PP. Potential exposure and health risks of infants following indoor residential pesticide applications. Am f Public Health 1990;80:689-93.

10 Delamothe T. Airs, waters, places, and doctors. BMF 1992;304: 268-9. (1 February.)

\section{Health risks associated with bathing in sea water}

SIR, - Short reports are a useful way of publishing case reports or series in which the message is simple. Epidemiological studies, however, are generally more complex, and it is unlikely that sufficient information about the control of potential biases and confounding can be given in short reports to allow readers to interpret the results critically.
This is exemplified by $\mathbf{R}$ Balarajan and colleagues' report of a study of health risks associated with sea bathing. 'The paper gives insufficient information for readers to assess whether the respondents were aware of the purpose of the study and might therefore have been biased in their responses to follow up questions, whether the interviewers were aware of the hypothesis under consideration, and what effect non-ownership of a telephone might have had. In addition, the validity of telephone reporting of symptoms by British respondents is unclear, although it may have been evaluated as part of the study.

The most persuasive finding in the study is the so called dose-response effect of different forms of immersion. These, however, are not defined, and it is unclear whether wading might be a dampening of the ankles or being in up to the bather's neck. Immersion of the head might be expected to confer a considerable risk, and it is not clear if this was included in any of the definitions. The second problem with this aspect of the study is whether the result might be due to confounding. Though age and sex were adjusted for (in an unspecified manner), other variables are potentially associated with both sea bathing and the range of outcomes reported, such as social class, smoking, and alcohol consumption. Were these recorded and were they confounders?

Finally, the study tested procedures for studies of the effect of sea bathing but not for bathing in contaminated water-for example, the strategy of examining the variation in contamination at each beach was not addressed.

The paper leaves us to conclude that the information is insufficient. Although the authors refer to other sources, these are unpublished reports that have not been peer reviewed. It seems preferable for research sponsored by the government to be published in a way that permits fully informed judgment of the findings. Certainly, the evidence presented in this paper alone does not justify the conclusion that the study's design is suitable for application. Judgment of the suitability of any study's design must depend on well documented, rigorous methodology

A J HALL

L C RODRIGUES

Communicable Disease Epidemiology Unit,

London School of Hygiene and Tropical Medicine, London WCIE 7HT

1 Balarajan R, Soni Raleigh V, Yuen P, Wheeler D, Machin D, Cartwright $R$. Health risks associated with bathing in sea water. $B M$ F 1991;303:1444-5. (7 December.)

AUTHORS' REPLY, - We agree with A J Hall and L $C$ Rodrigues that our most persuasive finding was the dose-response effect of different forms of contact with sea water: those bathing activities that entailed more immersion usually resulted in more symptoms being reported.

There are clearly difficulties in determining the precise degree of immersion of bathers without detailed questioning. We had estimated at the design stage of the study that the prevalence of self reported symptoms (particularly gastrointestinal symptoms, including diarrhoea) was likely to be low. This in turn implied that a large sample (2000 subjects in 19 days) would be required to obtain sufficient events for detailed analysis. We also knew that age and to some extent gender strongly influenced the type of sea water activity pursued, and these characteristics could easily be judged by the trained interviewers for quota sampling.

To avoid prolonging the interview at the beach questions were kept to a minimum so as to focus on key information such as a telephone number for contact; whether the subject lived locally or was a day tripper or holidaymaker at the resort; and the degree of contact with sea water. To distract from knowledge of the real hypothesis under question interviewees were asked if they had consumed
10 locally purchased foods (individually identified) on that day.

At the telephone interview the questions on sea water activity and on foods were repeated, and only then were subjects asked about their illnesses or symptoms after the interview at the beach. The interviewers at the beach were not aware of the questions about symptoms to be posed at the telephone interviews, which were conducted by a different team of interviewers, who were briefed to avoid reference to symptoms until the final stage of that interview.

Relative risks adjusted for gender and age were obtained with standard logistic regression models.

We agree that the validity of telephone reporting of symptoms is unclear, but we assume that, although overall reporting levels may be inflated, this should not distort the dose-response relation we observed. Follow up medical examinations are not feasible for this type of study.

Hall and Rodrigues are right to raise the question of relating the symptoms reported to bathing in contaminated sea water. As we indicated in our paper, the quality of the water varied appreciably day by day, and we also know that it varied by time of day and by location at each beach. Clearly, the proportion of bathers experiencing, for example, gastrointestinal symptoms can be plotted daily together with the quality of the sea water and relation between the series examined. Unfortunately, for analyses addressing this question and the responses about food consumed we have observed too few events; we await the data to be collected in August this year before we can complete these aspects of the study

In summary, we agree with the sentiment and points raised by Hall and Rodrigues, but the design of this study was a balance between what was desirable and what was achievable with the resources available.

R BALARAJAN V SONI RALEIGH P YUEN D MACHIN

Institute of Public Health

University of Surrey,

Guildford,

Surrey GU2 5XH

\section{Unnecessary radiology}

SIR,-Fiona Godlee in her very comprehensive article on environmental radiation' refers to the report from the Joint Working Party of the National Radiological Protection Board and the Royal College of Radiologists, ${ }^{2}$ which called attention to a study showing that some $33 \%$ of patients attending an orthopaedic clinic in Scotland had to have repeat $x$ ray examinations because their original films were not provided by their general practitioners. $^{3}$ There is a danger that this rate of $33 \%$ may become misconstrued as being the norm in orthopaedic clinics generally. One step towards misconstruction may have occurred already through a $B M \mathcal{F}$ editorial which, in referring to the Scottish survey, commented: "The missing radiograph is another cause of unnecessary exposure, and a survey in an orthopaedic clinic reported that a third of all patients had repeat examinations because of missing films - a bland statement of a shocking fact." ${ }^{\prime}$ The editorial was correct but did not mention two important aspects of the Scottish survey. Firstly, the survey was concerned only with referrals from general practitioners, and, secondly, most of the missing $x$ ray films had been taken at four health centres (G R Sutherland, personal communication) and at other hospitals away from the orthopaedic clinic.

To assess the repeat $x$ ray rate in a more typical English district hospital setting, we carried out the following audit. During a three week period in August and September 1991 we prospectively surveyed all patients attending 29 consecutive 